\title{
A Constructivism-based 3D Scene Display Teaching System for Wushu Teaching
}

\author{
https://doi.org/10.3991/ijet.v12i01.6485 \\ Zhengmei Jin \\ Bengbu Medical College, Bengbu, Anhui, China \\ $13721181220 @ 163 . \mathrm{com}$
}

\begin{abstract}
With the introduction of the teaching theory of constructivism and the development of virtual 3D technology, multimedia courseware production is required to enhance the authenticity of teaching situation, expand the interaction of teaching courseware, and carry out 3D network teaching. This paper designed a constructivism-based 3D scene display teaching system. By using ASP.NET and WEB3D as the core technologies and combining SQL SERVER technology, this system can run on the Internet in the form of web pages, demonstrate and store teaching courseware, and show great advantages in human-computer interaction, three-dimensional display and advanced teaching. In specific discussion, the paper elaborated the demand of designing the system, relevant function modules and the implementation process. It has been proven that the constructivism-based 3D scene display teaching system for $\mathrm{Wu}-$ shu education has a remarkable effect on improving students' examination results and expanding their innovation ability.
\end{abstract}

Keywords - 3D scene display, teaching system, Wushu, constructivism, interactive technology

\section{$1 \quad$ Introduction}

3D technology is a technical system constructed based on the difference of people's binocular vision. It produces active stereo and passive stereo vision in people's eyes, giving a visual effect of watching 3D scene [1]. 3D technology could be divided into diverse categories, mainly covering Film Patterned Retarder (FPR) technology, complementary color technology, time-sharing technology, holographic technology, etc. At present, the mainstream 3D technology in the market includes holographic technology, VR virtual imaging technology and so on. Each of the technologies in whatever type is able to bring the visual effect of three-dimensional imaging. Hsu et al. (2014) combined 3D technology and technology equipment in museums. To achieve the aim of supporting natural interaction of visitors during museum presentations on the basis of using cameras, they first outlined the "U-Garden", a platform 
composed of various tools which are useful for application designers to develop motion-based projects that adopt camera tracking. A rationale with which to base the design of these presentation tools was then established. This system provides designers with tracking results for generating countless fascinating applications appealing to more diverse interactive imaginations and offers interactive power to natural interaction based on depth image streams [1]. 3D technology has become the focus of attention in the education sector and is increasingly being applied to a variety of courses. However, there is still a lack of research on the construction of $3 \mathrm{D}$ scene display teaching system in the teaching of Wushu.

\section{Review of Research Progress}

In view of its imaging advantages, 3D technology has been increasingly applied to the field of modern education in recent years, accompanied by more and more corresponding studies by domestic and foreign scholars. Boulay et al. (2015) employed 3D technology in the teaching of emergency treatment. In the experiment, they scientifically evaluated an interactive AO team interface concerning Learnability and Usability outcomes in two contexts: an 'online' setting in which individual Team Users might be separated in time and space and team immersive interaction in which all Users are physically present. The experimental results show that the use of 3D technology can improve the teaching effect [3]. An immersive audio rendering scheme was proposed by Lim et al. (2014) to support networked 3D multimedia systems. They used a variety of sound sources in experimental validation and numerical analysis. As shown and confirmed by the experimental results, the developed approach could be utilized to generate various virtual audio objects at target positions with quite high accuracy while covering the majority of the listening area [4]. Yuan et al. (2015) put forward the advantages and development prospects of 3D MAX technology in solving problems with regard to the teaching of technical tennis actions. 3D animation acquires quantitative data through video capture. On the basis of post-production, tennis beginners have the opportunity to selectively accept a full range of technical demonstrations. The outcomes demonstrate that 3D technology can not only promote the teaching effect, but also increase students' self-learning ability [5]. Zhou et al. (2016) used Autodesk 123D Catch to achieve 3D modeling of pictures of human body structure, and employed 3Ds Max software to modify and render the 3D human body model, set lights and construct the 3D human structure or organ. Through the interface designed based on Unity, the 3D structure could finally be presented in the computer or mobile phone. The results confirm the possibility to produce the anatomical $3 \mathrm{D}$ digital model in line with the purpose of medical teaching and operate in the computer or mobile phone to facilitate teaching [6].

It can be seen that $3 \mathrm{D}$ technology has become the focus of attention in the education sector technology. Nevertheless, there are still some shortcomings regarding 3D technology. First of all, the combination of 3D technology and interactive technology with action teaching is not common in China. Instead, Wushu and other action teaching are often conducted in the form of the traditional one-to-one and face-to-face 
guidance, resulting in significant influence on student's learning effect [7]. Moreover, in the process of 3D teaching, the existing 3D display technology can only allow the viewer to see a single $3 \mathrm{D}$ scene, rather than see the 3D scene from different angles. For example, when watching a Wushu action in a 3D scene, the one who stands on the observing position A can generally observe only a 3D picture of action, but cannot see the back and side picture of that action. Consequently, the viewing experience of the user is reduced [8].

According to the background above, this paper elaborated a $3 \mathrm{D}$ scene display teaching system design based on the ternary technology system of ASP + WEB3D + SQL SERVER, and combined with the theory of constructivism to introduce and realize a method of displaying 3D images as well as its installation. Meanwhile, the system can capture eye information of the viewer in real time and determine the observing position of the viewer in accordance with the captured eye information, so as to solve the problem that the current 3D multimedia teaching cannot deal with, namely, the viewer cannot observe different 3D images in 3D scene with the change of the observing position. This system is somewhat innovative and advanced, and could provide reference for the research and innovation on the same topic.

\section{Theoretical Basis}

\subsection{Theory of constructivism}

Constructivism [9] is a theory of knowledge and learning which emphasizes the learner's initiative. It believes that learning is the process for the learner to generate meaning and construct understanding based on his or her original knowledge and experience. In addition, this process is often completed in social and cultural interaction. The proposal of constructivism has profound ideological origins. With the learning theory and teaching thought different from the traditional ones, it brings important guiding value for teaching design [10]. The use of constructivism in guidance of multimedia courseware design not only allows multimedia courseware to get rid of constraints from the traditional teaching theory, so that it no longer serves as an electronic blackboard in teaching but acts as the carrier of teaching situation and the tool for students to construct meaning, but also makes the learning process become more intuitive, enhances people's understanding of constructivist learning theory, and promote people's mastery of constructivist learning methods. Thus, it has gradually become the fundamental theory to guide multimedia courseware production. The basic structure of courseware production based on the theory of constructivism is shown in Figure 1. 


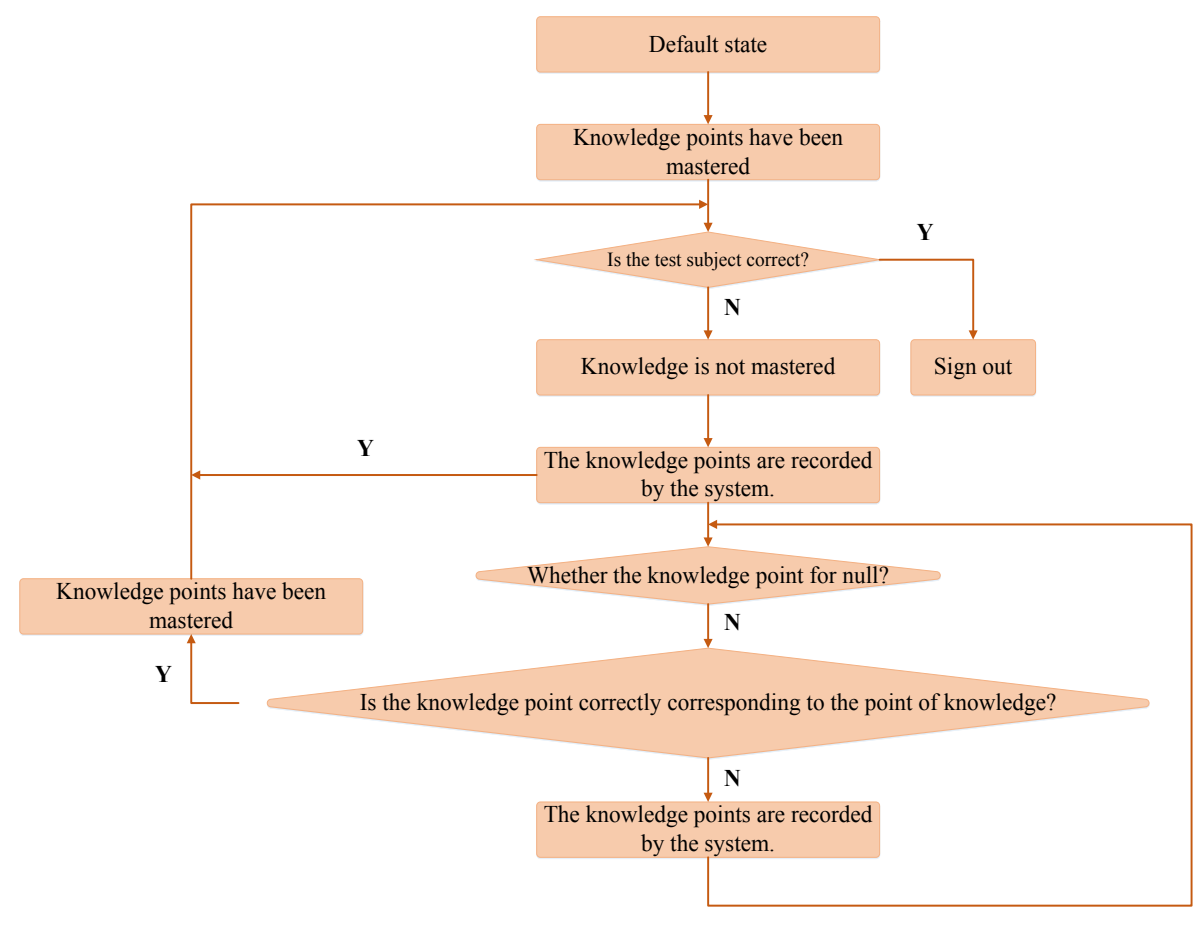

Fig. 1. The basic structure of the theory of constructivism

\subsection{Design of the constructivism-based 3D scene display teaching system}

(1) Design of the 3D scene display teaching system for meaning construction

The theory of constructivism argues that: "Learning is the process of acquiring knowledge, and knowledge is passed on to students by teachers, but obtained by students in the way of theoretical construction in the process of using necessary learning resources such as text materials, audio-visual materials, CAI courseware, and information obtained from the Internet in the social and cultural context with the help of teachers or classmates [11]. The theory places emphasis on student-centered learning, viewing students as the subjects of cognition and the active constructors of knowledge meaning. Under the guidance of constructivism, the 3D scene display teaching system for Wushu education is required to be based on the thought of learning as the core in every stage like creating scenes, setting interaction and providing resources.

(2) Setting powerful interactive functions to establish the 3D scene display teaching system

Constructivism believes that learners "make use of the assistance from teachers and classmates" to enrich and expand their understanding of knowledge through cooperative communication. Currently, the main interactive settings used in 
multimedia courseware of Wushu to achieve the interaction between teachers and students are: BBS system, QQ, message sent via mobile phone, WeChat and e-mail. We can see that the students always comment on the courseware scene outside the courseware scene. 3D technology used in this study not only offers interactive settings usually seen in movies and animations, but also provides the user with control over the player and camera. The user can rotate the player model by dragging the mouse and achieve panning, pushing and pulling of the camera via the arrow keys. In this way, the user can observe any movement part of the player from any angle and distance and thereby can form clear, correct and comprehensive action concept and motion visual representation as soon as possible, to improve the efficiency of teaching. The basic structure of the interactive 3D scene display teaching system is shown in Figure 2.

(3) Using various resources to establish the 3D scene display teaching system

If the technical action itself demonstrated in the film or animation is wrong, it will form a false visual representation among students at the beginning of teaching. Then, even if the courseware does well in other aspects, it is futile. The use of 3D scanner modeling in conjunction with optical motion capture system, as well as virtual reality display technology, can also achieve technical actions at the standard demonstrated in the film, as shown Figure 3.

\section{Implementation of the 3D Scene Display Teaching System}

\subsection{Design idea of the 3D scene display teaching system}

The design idea is: desktop virtual reality technology and web 3D technology could be used to create courseware which could stimulate students' interest more easily and reinforce interactivity. Specifically, 3D which displays technical actions as realistically as a film does, achieves 3D interaction and facilitates network transmission (a popular technology in desktop virtual reality and web3d) is used for media display in place of the traditional technology-based action film, to demonstrate the complete decomposed actions respectively. In the process of displaying technical actions, in addition to implementing the common interactive functions that can be realized in the technical film, the media should also have interactive functions similar to those provided in three-dimensional game, such as control over the camera and the player model, to arouse students' interest and reach the aim of allowing students to watch the display of technical action from any angle and distance according to their own will through operating the keyboard and mouse. The basic design idea is shown in Figure 4.

\subsection{Multi-angle shooting technology for 3D scene}

The teaching module of the platform is divided into two parts: the front end and the back end. In the development of the front end, WEB3D technology was used 


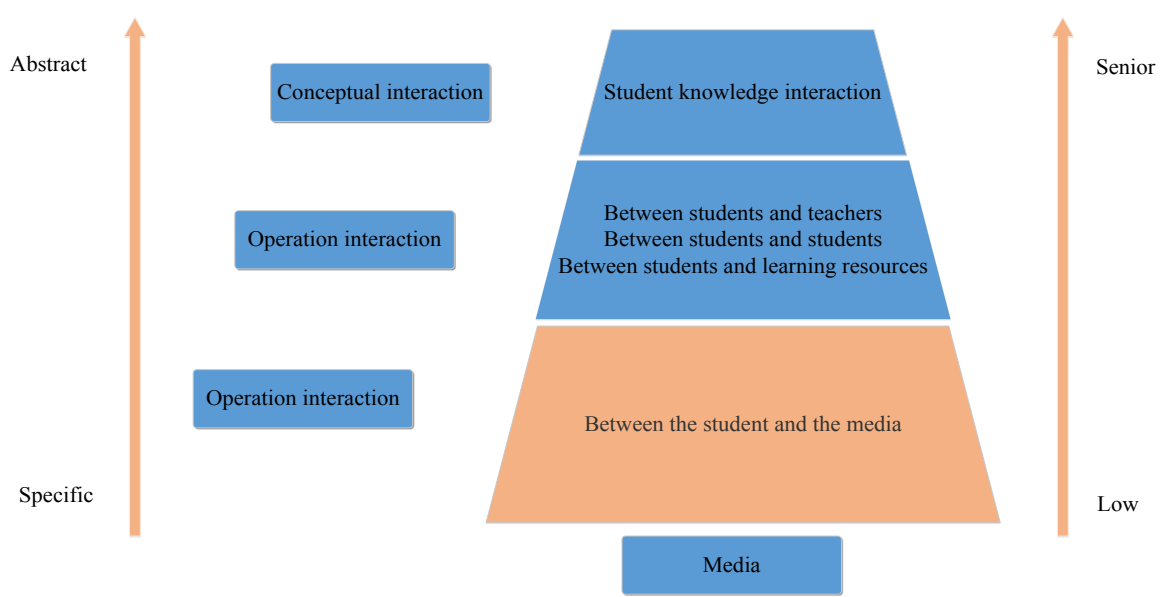

Fig. 2. Basic structure of the interactive 3D scene display teaching system

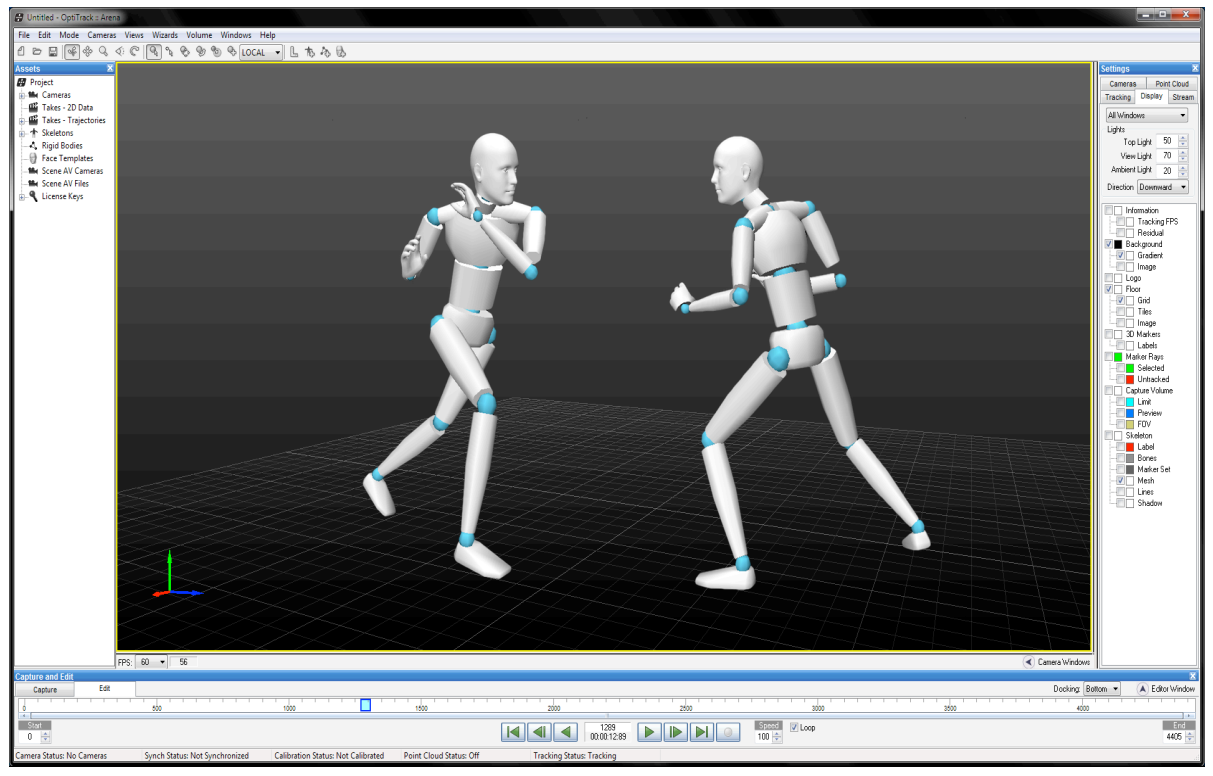

Fig. 3. Courseware production by $3 \mathrm{D}$ scanner modeling in conjunction with optical motion capture system

to construct the courseware demonstration interface. The specific design idea is: $3 \mathrm{D}$ scene information is loaded in the $3 \mathrm{D}$ scene display teaching system. The scene information contains 3D image information from multiple shooting positions. Indisplay, the shooting devices at different angles are capable of capturing images of the Wushu practitioner at different positions and generating 3D presentation dynamic 
effect graphic or video at a viewing angle. The effect graphic or video can be uploaded through the transmission device in the system to the WEB3D page and finally be displayed in front of the learner. The presentation diagram of 3D courseware from different angles is demonstrated in figure 5.
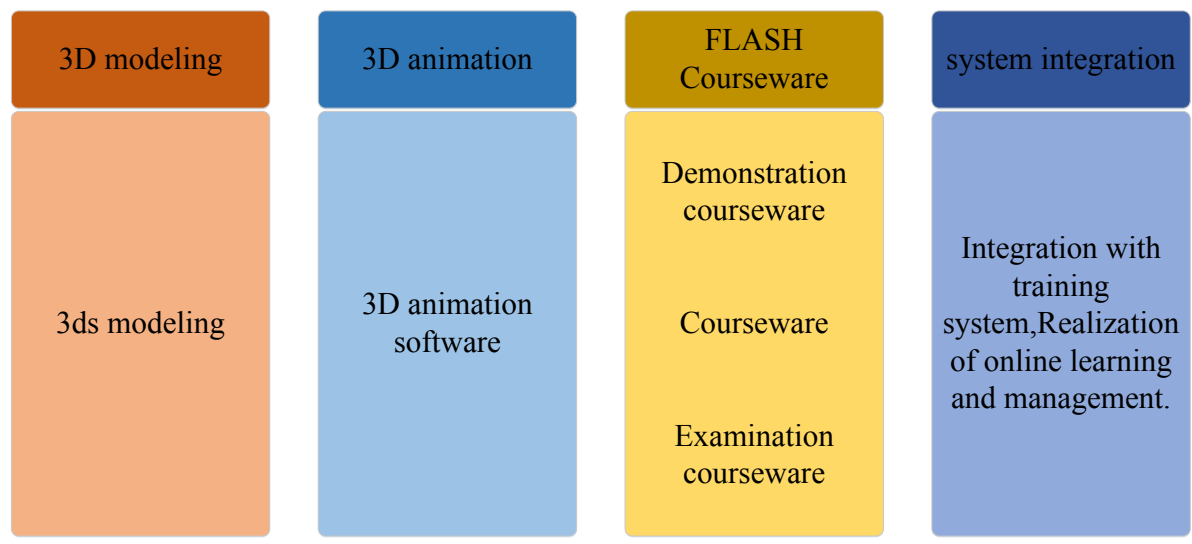

Fig. 4. Framework of the Teacher-controlled Teaching mode

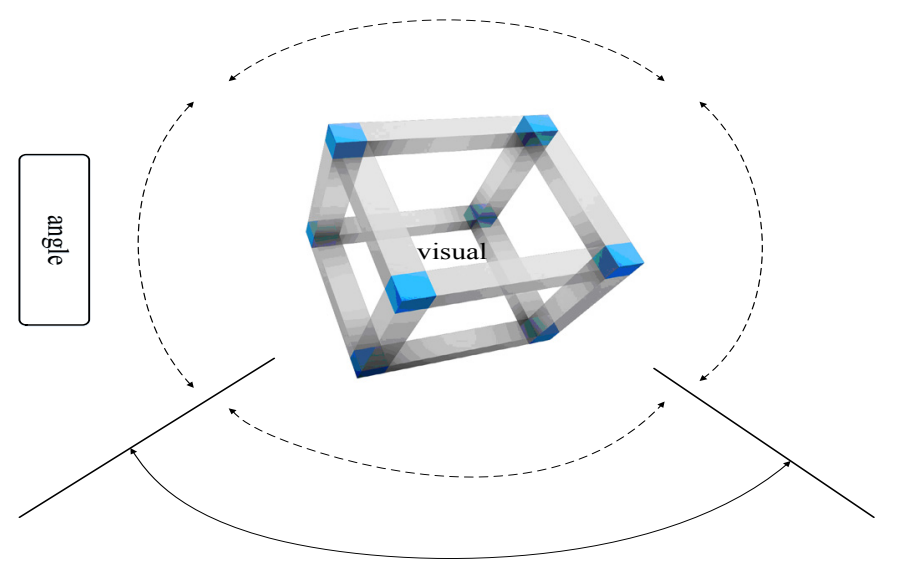

Fig. 5. Presentation diagram of 3D scene courseware from different shooting angles

\subsection{Segmentation of 3D scene foreground and background}

An improved image segmentation algorithm based on GrabCut was referred to make it which is suitable for image extraction of multiple foreground objects. GrabCut algorithm is essentially an improvement on graph cut algorithm. The main idea of GrabCut algorithm is to use texture information and boundary information in 
the image to segment the image. Based on GrabCut, this paper divided the image into multiple sub-images and computed the multiple sub-images in parallel to improve the speed of image segmentation on a number of foreground objects.

The basic idea of GrabCut algorithm is: firstly, a rectangular box is used to mark the region of foreground extraction in the image by user interaction, to obtain a hard segmentation. A graph cut technique is used to determine the optimal patch region for any given offset between the input and output texture. Unlike dynamic programming, our graph cut technique for seam optimization is applicable in any dimension. Then, the Gaussian mixture model (GMM) replaces the gray-scale histogram to initialize each pixel; afterwards, the iterative optimization method is utilized to minimize the Gibbs energy function:

$$
\begin{aligned}
& E(\alpha, k, \theta, z)=U(\alpha, k, \theta, z)+V(\alpha, z) \\
& E(\alpha, k, \theta, z)=\sum_{i=1}^{n} E_{i}(\alpha, k, \theta, z)
\end{aligned}
$$

Where $\alpha$ refers to the opacity and $\alpha \in[0,1] ; 0$ is the background; 1 is the foreground; $\theta$ is the gray-scale histogram of foreground and background of the image; $\mathrm{k}$ is the independent GMM parameter of each pixel. Through minimizing the Gibbs energy, GrabCut algorithm ultimately assigns a $\alpha$ value for each pixel in the image, to achieve the result of image segmentation.

\subsection{Formation of the 3D scene display teaching system for Wushu education}

When the 3D courseware is created, goes through foreground and background segmentation, and is finally uploaded to the WEB3D page, the user can click the online play button to watch the corresponding picture or video of Wushu practice. To complete the communication between the WEB3D page and 3D courseware database, background design of the system needs the ASP.NET technology design support system. The teaching system can display the 3D scene Wushu courseware. The figure 6 gives an interface of 3D Wushu teaching demonstration scene.

\section{Test of the Wushu scene display teaching system}

To test the effectiveness of the teaching system in Wushu education, Class (3) (the Experimental Class) and Class (4) (the Control Class) of Grade 2014 majoring in Wushu were chosen as the objects of the experiment and 15 students in each class. In specific practice, the traditional lecture method was used to teach Class (4), while teaching in Class (3) relied on the 3D scene display courseware platform. The results after 56 hours of teaching are shown in table 1 and table 2. 


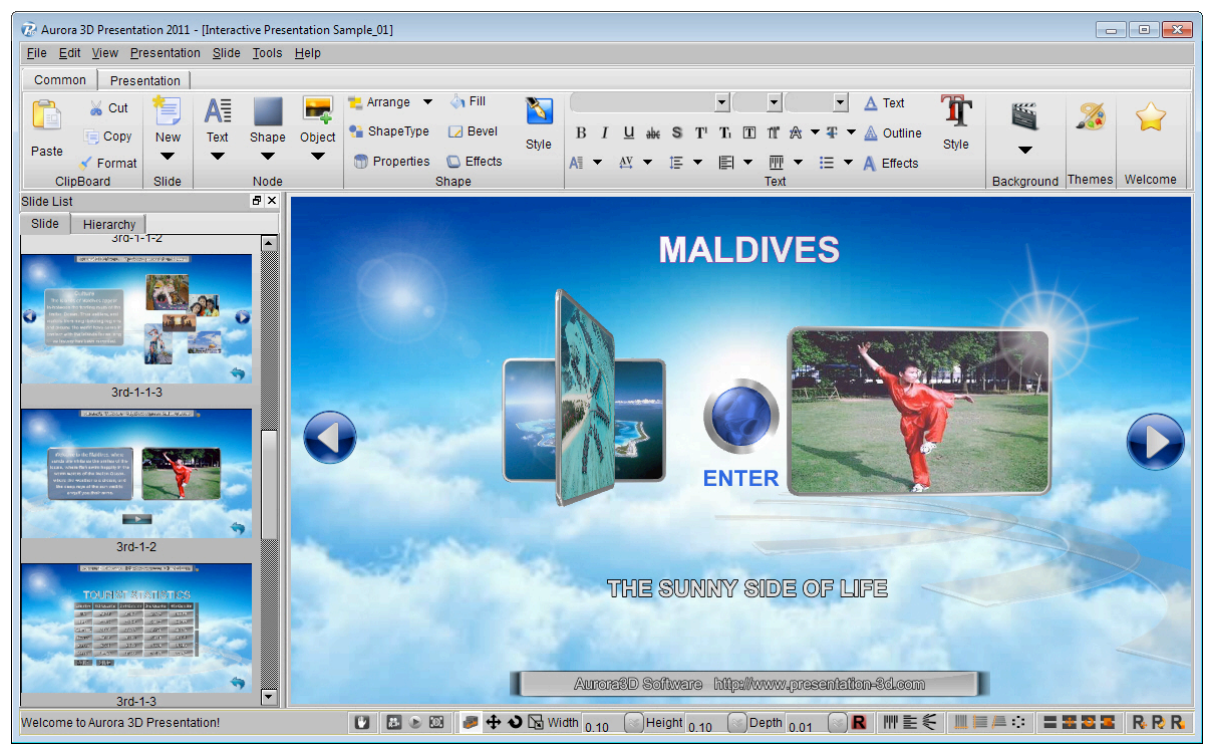

Fig. 6. 3D scene Wushu courseware

TABLE 1. Average Scores Of The Experimental Class And The Control Class In The Final Exam (Points,, $\mathrm{X}+\mathrm{S})$

\begin{tabular}{lcccc}
\hline \multicolumn{1}{c}{ Indicator } & \multicolumn{2}{c}{ Average score } & \multirow{2}{*}{ t } & P \\
& Experimental class & Control class & & \\
\hline Theoretical results & 47.5 & 22.6 & 3.35 & 0.001 \\
Training results & 43.5 & 31.2 & 3.51 & 0.002 \\
Total score & 91.0 & 53.8 & 4.12 & 0.003 \\
\hline
\end{tabular}

Table 2. Self-evaluation on learning effect by the experimental class (points, , , $\mathrm{x}+\mathrm{s}$ )

\begin{tabular}{lc}
\hline \multicolumn{1}{c}{ Evaluation item } & Experimental class \\
\hline Increase interest in learning & $9.67+2.35$ \\
Conducive to improving self-learning ability & $9.56+1.38$ \\
Conducive to improving innovation capacity & $9.22+3.21$ \\
\hline
\end{tabular}

According to the data in Table 1, the average score of the students in the experimental class in the final exam is significantly higher than the control class, and there is difference in the statistical results. Meanwhile, the data in Table 2 offer the real reflection of students in the experimental class. They believe that the platform can improve students' interest in learning "Wushu" and is conductive to improving their self-learning ability and innovation ability. Therefore, the platform is of great help to increase the quality of teaching "Wushu" in colleges and universities. 


\section{Conclusion}

In the current age when information technology and 3D technology continue to develop and spread, the introduction of 3D dynamic display technology into Wushu education in colleges and universities will not only enrich the teaching means of teachers and enhance the advancement of teaching, but can also rely on the intelligence and vision effect of 3D technology to create more realistic scenes for both parties in teaching, to provide more basis for teaching design, to realize dynamic, interactive classroom teaching, to generate more diverse teaching conceptions, and to promote the leap in the effectiveness of curriculum teaching. In this study, when the design idea of role-playing 3D game was employed to guide the production of multimedia courseware, students could control their own role in the specific virtual education scenario, engage in collaboration, conversation and other communication activities, and complete the assigned learning tasks, so that their virtual character will be promoted to higher levels, and at the same time, they can acquire relevant knowledge. This novel and scientific teaching technology is clearly able to improve students' interest, and in the learning process, it will further stimulate students' ability to innovate through experiencing and contacting high-tech teaching equipment. As a consequence, students will accumulate the capacity to design and arrange Wushu actions in the future.

This study integrated 3D, virtual technology, multi-angle shooting and other technologies to establish a constructivism-based 3D scene display teaching system for Wushu education. The system realizes multi-angle display, movement superimposition and stage play of technical actions. Besides, it also adapts to the development of modern education and meets the requirements of constructivism. It is a direction of developing virtual reality technology and provides reliable reference for further improving the authenticity and extensibility of sports and other action teaching courseware.

\section{$7 \quad$ References}

1. Hollaus, K., \& Schöberl, J. "Multi-scale FEM and magnetic vector potential A for 3D eddy currents in laminated media," COMPEL: The International Journal for Computation and Mathematics in Electrical and Electronic Engineering, vol. 34, no. 5, pp. 1598-1608, October 2015.

2. Hsu, F.S., \& Lin, W.Y. "A multimedia presentation system using a 3D gesture interface in museums," Multimedia Tools and Applications, vol. 69, no. 1, pp. 53-77, March 2014. https://doi.org/10.1007/s11042-012-1205-y

3. Boulay, A.J., \& Grewal, R. "An Advance Organizer for 3D VR Training Simulations and Social Media'Multi-Operator'training systems," In EdMedia: World Conference on Educational Media and Technology, no. 1, pp. 764-771, June 2015.

4. Lim, H., Kim, C., Ekmekcioglu, E., Dogan, S., Hill, A.P., Kondoz, A.M., \& Shi, X. "An approach to immersive audio rendering with wave field synthesis for 3D multimedia content," In 2014 IEEE International Conference on Image Processing (ICIP), pp. 76-80, October 2014. https://doi.org/10.1109/ICIP.2014.7025014 
5. Yuan, S.M., \& Zhang, M.Q. "Design of tennis-aided teaching model based on 3D MAX," Contemporary Sports Technology, vol. 4, no. 9, pp. 187-188, September 2014.

6. Zhou, Y., Xu, Z.K. "Digital 3D interactive model making technology for human anatomy structure," China Medical Education Technology, vol. 30, no. 4, pp. 505-507, August 2016.

7. Chen, H.R., \& Wang, H.C. "Research on the Key Technology of 3D Virtual Teaching System Based on Silverlight," Information Technology \& Informatization, no. 4, pp. 188-189, April 2014.

8. Zeng, Y.C. "Problems of three-dimensional software (3D MAX) in teaching and solutions," Time Education: Education and Teaching Edition, vol. 13, pp. 134-134, July 2012.

9. Adler, E. "Seizing the middle ground: constructivism in world politics," European journal of international relations, vol. 3, no. 3, pp. 319-363, September 1997. https://doi.org/10.1177/1354066197003003003

10. Raskin, J.D. "Constructivism in psychology: Personal construct psychology, radical constructivism, and social constructionism," American communication journal, vol. 5, no. 3, pp. 1-25. June 2002.

11. Gupta, S. "Constructivism as a paradigm for teaching and learning," International Journal of Physical and Social Sciences, vol. 1, no. 1, pp. 23-47, October 2011.

\section{Author}

Zhengmei Jin is a Lecturer of Bengbu Medical College, Bengbu 233030, Anhui, China. Her research interests include physical education, Inductive 3D Scene Display and Multimedia Teaching. (13721181220@163.com)

Submitted 03 December 2016. Published as resubmitted by the author 10 January 2017. 